\title{
Changes in the Refraction and Visual Acuity of Patients during a Period of the First Month after Phacoemulsification Surgery
}

\author{
Pateras $\mathrm{E}^{1 *}$, Alonistiotis $\mathrm{D}^{2}$, Hyska $\mathrm{B}^{3}$ and Tsiantakou $\mathrm{G}^{3}$ \\ ${ }^{1}$ Associate Professor, Biomedical Department, Course of Optics and Optometry, Greece \\ ${ }^{2}$ Ophthalmologist, Lecturer, 2nd University Clinic of Ophthalmology, Greece
}

${ }^{3}$ Student, Biomedical Department, Course of Optics and Optometry, Greece

*Corresponding author: Pateras E, Associate Professor, Biomedical Department, Course of Optics and Optometry, Athens, Greece

\begin{tabular}{|c|c|}
\hline ARTICLE INFO & ABSTRACT \\
\hline Received: 幽 April 10, 2019 & $\begin{array}{l}\text { Citation: Pateras E, Alonistiotis D, Hyska B and Tsiantakou G. Changes in the Refraction } \\
\text { and Visual Acuity of Patients during a Period of the First Month after Phacoemulsification }\end{array}$ \\
\hline Published: 㹃 April 22, 2019 & Surgery. Biomed J Sci \& Tech Res 17(2)-2019. BJSTR. MS.ID.002973. \\
\hline
\end{tabular}

\section{Introduction}

The crystalline lens of the eye is a transparent and biconvex structure, which is placed at the posterior chamber of the eye, between the iris and the vitreous humor [1-3]. The lens is suspended in place by the radially arranged zonules fibers. Also, is anatomically composed by a surrounding capsule, the epithelial cells, which are placed at the posterior surface of the capsule and the lens fibers, which is the main substance of the crystalline lens (cortex and nucleus). The main function of the lens is to contribute to the refraction of light and its focus on the retina. When beholding a far distance object, the image of the target on the retina is well focused and we decide to focus at a near distance object, increasing the refractive power of the eye is necessary, so as to have the image of the target on the retina always well focused (accommodation).

What we know today about the mechanism of accommodation are based on the theory of Helmholtz (1856) Therefore, when looking in far distance, the ciliary body is relaxed and its diameter increases, keeping the zonules fibers tense. As a result, the curvature of the crystalline lens decreases (the lens becomes flatter).

During accommodation, the ciliary muscle decreases in diameter, while the fibers get loose. Then the elastic capsule of the crystalline lens, regains its physiological curved form. Over time, the lens loses its elasticity and become harder, inflexible and more opaque in color As a result, the lens loses the ability of accommodation. The gradual loss of the crystalline lens clarity is the pathological eye condition of cataract and is treated surgically (Figure 1).

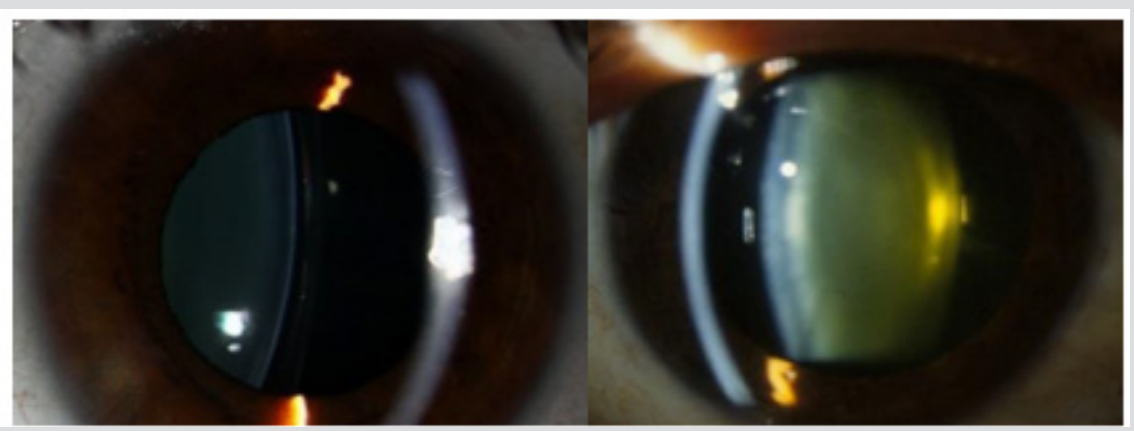

Figure 1: Natural crystalline lens (left) - Crystalline lens with cataract (right). 


\section{Phacoemulsification Technique}

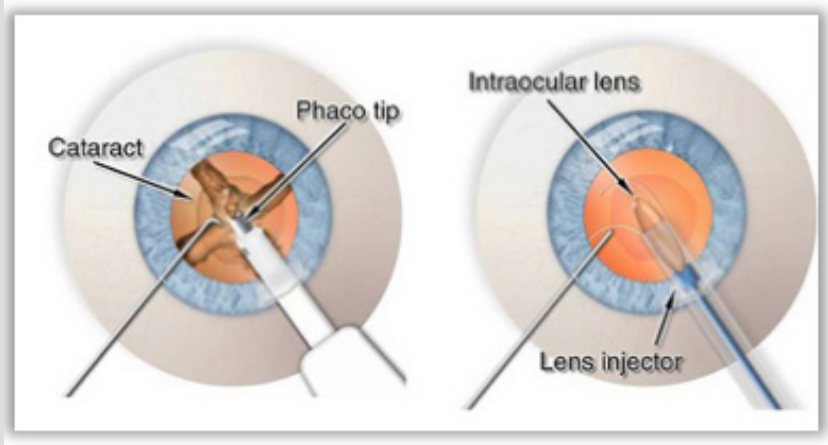

Figure 2: Presentation of crushing the nucleus and emulsification.

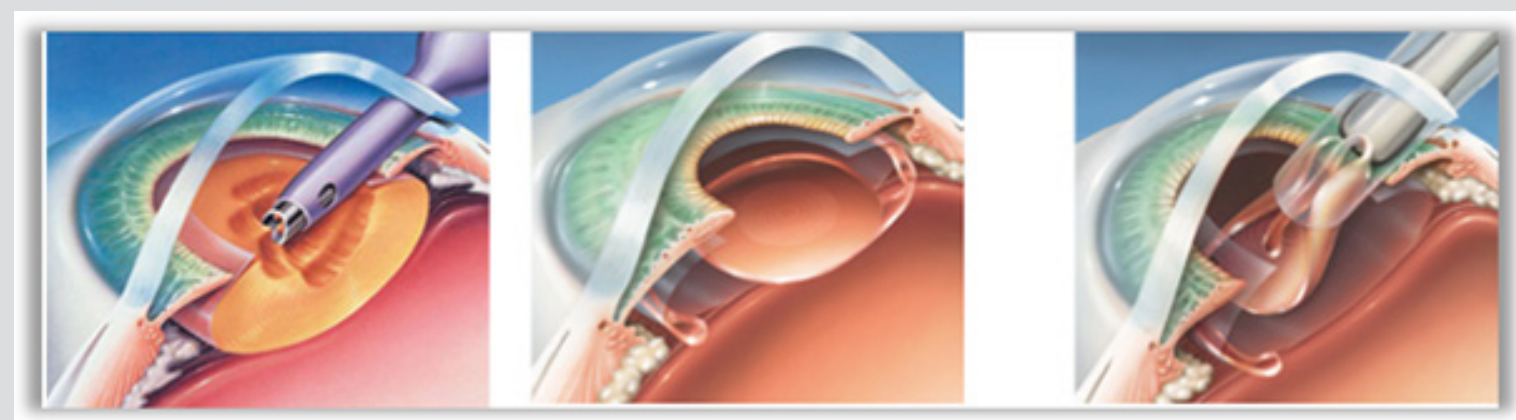

Figure 3: Crushing the nucleus of the crystalline lens during phacoemulsification surgery and insertion of the IOL.

In our days, phacoemulsification [1-3] is the most widespread method of surgical treatment of cataract. The main advantages of this technique are the successful removal of the crystalline lens through a small incision, the reducing of the hospitalization period, the avoidance of intraoperative and postoperative complications and the accelerating of postoperative visual rehabilitation of the patient. During this technique, the nucleus of the crystalline lens gets emulsified by a ultrasonic handpiece and the crushed parts are get removed from the anterior chamber of the eye by an irrigationaspiration probe. Finally, a new intraocular lens (IOL), that replaces the crystalline lens, is placed inside the empty capsule. From the April to June of 2017, at "ATTIKON" Athens University General Clinic, a clinical study took place. The purpose of the study was to examine the evolution of the refraction of eighteen patients, during the first month after phacoemulsification surgery. Also, the study aims to investigate, if the cases that were examined developed the technique's main advantages [4, 5-9]. Of the total of eighteen patients, eleven were women and seven were men. Their ages fluctuated between the ages of 49 and 88 . They were operated by the same surgeon, who followed the same surgical process in all cases (Figures 2 \& 3).

Fifteen and thirty days after every patient's surgical treatment, a check of the operated eye's refraction was held. Special attention was paid to the evolution of visual acuity. Of all patients, two people showed findings of dry type of age-related macular degeneration, preoperatively. In the first case (No 6), this condition affected the visual acuity of the patient and remained in low levels, postoperatively. In the second case (No 11), the visual acuity of the patient improved and didn't get affected by this pathological condition. In two people, also, appeared aspects on the Descemet's membrane fifteen days after phacoemulsification. As a result, the first patient (No 8) ended with low visual acuity and the second patient (No 18) ended with secondary myopia, because of corneal edema.

\section{Presentation of Astigmatism Changes}

Fifteen days after phacoemulsification, four patients developed an unimportant amount of stigmatism, between $0-0.25 \mathrm{D}$ and six patients developed between $0.50-0.75 \mathrm{D}$. From the eighteen patients, six developed astigmatism between $1.00-1.25 \mathrm{D}$ and two of them an amount of $1.75 \mathrm{D}$. In total, all cases concluded with a postoperative astigmatism. The highest rate was at $1.75 \mathrm{D}$, which is not considered important as it's going to decrease in the next few days. At the refractive check, thirty days after the surgery, there was a little improvement in the astigmatic error. Six patients developed an unimportant rate of astigmatism between $0-0.25$ $\mathrm{D}$, five developed an astigmatic rate between $0.50-0.75 \mathrm{D}$ and six developed astigmatism between 1.00 - 1.75 D. Finally, only one case developed a high rate of astigmatic error, at $2.00 \mathrm{D}$. In conclusion, out of the eighteen clinical cases, six people developed astigmatism "with the rule", from 0.50 to $1.50 \mathrm{D}$, four patients ended with zero astigmatism and seven patients developed "against the rule" astigmatism from 0.25 to $1.00 \mathrm{D}$. A special clinical case, was one patient (No 18), who had a final increase in astigmatism, at 2.00 $\mathrm{D}$, because of a pterygium, which entering the cornea caused a refractive error (Table 1). 
Table 1: Presentation of astigmatism changes ,15 and 30 days after phacoemulsification surgery.

\begin{tabular}{|c|c|c|c|c|}
\hline \multirow{2}{*}{ Number of Patients } & \multicolumn{2}{|c|}{ POST-OP CYL (15 DAYS) } & \multicolumn{2}{|c|}{ POST-OP CYL (30 DAYS) } \\
\hline & Cyl & AXIS & Cyl & AXIS \\
\hline 1 & $-0,5$ & 15 & $-0,25$ & 80 \\
\hline 2 & $-1,75$ & 70 & $-1,25$ & 75 \\
\hline 3 & $-1,25$ & 90 & $-1,5$ & 106 \\
\hline 4 & $-0,25$ & 5 & $-0,5$ & 160 \\
\hline 5 & 0,5 & 170 & 0,5 & 170 \\
\hline 6 & 1 & 75 & 0,75 & 70 \\
\hline 7 & $-0,75$ & 20 & 0,75 & 90 \\
\hline 8 & 1,75 & 20 & $-1,75$ & 100 \\
\hline 9 & 0 & 0 & 0 & 0 \\
\hline 10 & -1 & 90 & -1 & 90 \\
\hline 11 & $-0,5$ & 80 & $-0,25$ & 11 \\
\hline 12 & $-0,25$ & 115 & 0 & 0 \\
\hline 13 & 0 & 0 & 0,5 & 106 \\
\hline 14 & 1,25 & 40 & 1 & 130 \\
\hline 15 & -1 & 114 & -1 & 90 \\
\hline 16 & $-0,5$ & 45 & 0 & 0 \\
\hline 17 & $-0,5$ & 165 & 0 & 0 \\
\hline 18 & -1 & 96 & -2 & 90 \\
\hline
\end{tabular}

\section{Presentation of the Spherical Component of Refraction Changes}

Fifteen days after the phacoemulsification, four patients developed a low myopic error, ranging from 0.25 to $0.50 \mathrm{D}$. Eight clinical cases, also, developed a zero sphere and the other six developed a low hyperopic error, from 0.25 to $0.50 \mathrm{D}$. Thirty days after the surgical treatment, the noticed changes were very small, as we were already talking about a negligible sphere. As a result, the sphere remained stable in nine of the eighteen clinical cases, decreased by $0.25 \mathrm{D}$ in three cases and small increase of $0.25-0.50$ D, was noticed in six patients.

\section{Presentation of Visual Acuity before and after} Surgery

The preoperative sphere and astigmatism weren't included as clinical data in the study, because special attention was

Table 2: Presentation of visual acuity.

\begin{tabular}{|c|c|c|c|c|}
\hline Patients & PRE-OP VA & POST-OP VA (15 days) & $\begin{array}{c}\text { POST-OP VA without glasses } \\
\text { (30 days) }\end{array}$ & $\begin{array}{c}\text { POST-OP VA with glasses } \\
\text { (30 days) }\end{array}$ \\
\hline 1 & 0,4 & 0,5 & 0,9 & 1 \\
\hline 2 & 0,4 & 0,4 & 0,7 & 1 \\
\hline 3 & 0,4 & 0,6 & 0,3 & 1 \\
\hline 4 & 0,05 & 0,4 & 0,5 & 0,7 \\
\hline 5 & 0,3 & 0,5 & 0,7 & 0,7 \\
\hline 6 & 0,15 & 0,7 & 0,8 & 0,9 \\
\hline 7 & 0,3 & 0,7 & 0,6 & 0,9 \\
\hline 9 & 0,05 & 0,4 & 0,8 & 1 \\
\hline
\end{tabular}




\begin{tabular}{|c|c|c|c|c|}
\hline 10 & 0,3 & 0,7 & 0,7 & 0,8 \\
\hline 11 & 0,2 & 0,7 & 0,9 & 0,9 \\
\hline 12 & 0,2 & 0,6 & 0,7 & 0,8 \\
\hline 13 & 0,4 & 0,6 & 0,7 & 1 \\
\hline 14 & 0,2 & 0,7 & 0,9 & 1 \\
\hline 15 & 0,5 & 0,9 & 1 & 0,9 \\
\hline 16 & 0,05 & 0,8 & 0,9 & 0,8 \\
\hline 18 & 0,3 & 0,8 & 0,6 & 0 \\
\hline
\end{tabular}

\section{Statistical Study}

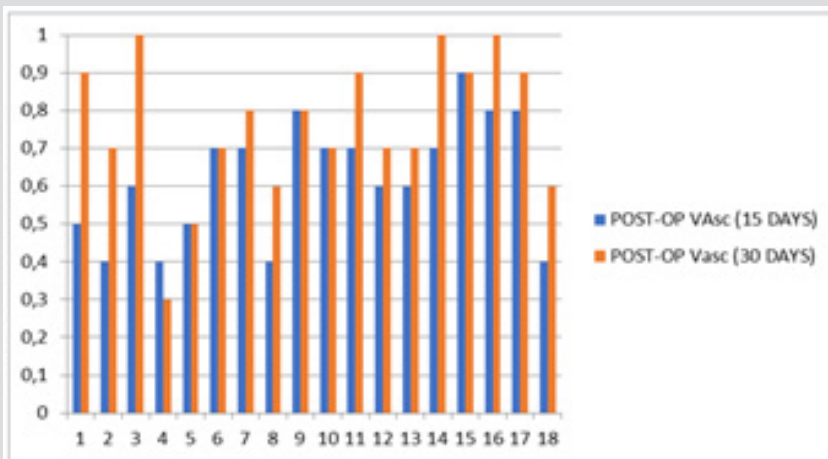

Figure 4: Changes of visual acuity post-operative 15 days \& 30 days.

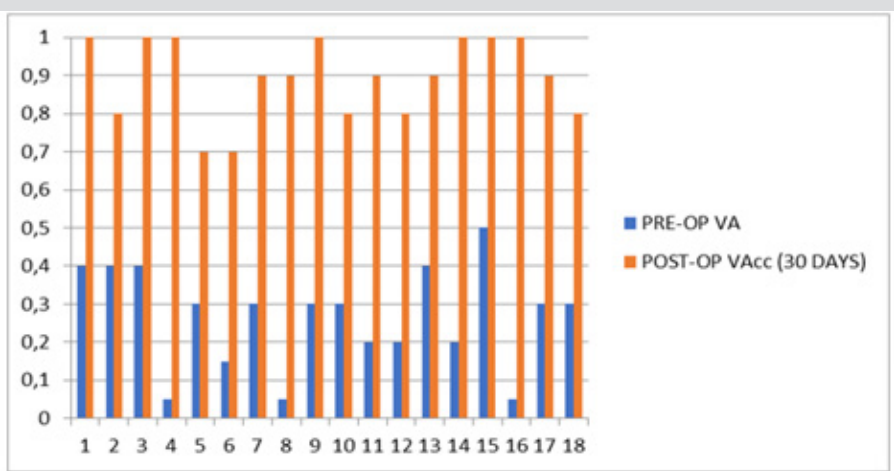

Figure 5: Changes of visual acuity pre-operative and 30 days after with glasses.

Table 3: Post-operative visual acuity.

\begin{tabular}{|c|c|c|c|}
\hline Number of eyes & V.A. without glasses & Number of eyes & V.A. with glasses \\
\hline 9 & $5 / 10 \rightarrow 7 / 10$ & 6 & $7 / 10 \rightarrow 8 / 10$ \\
\hline 9 & $8 / 10 \rightarrow 10 / 10$ & 12 & $9 / 10 \rightarrow 10 / 10$ \\
\hline
\end{tabular}

Table 4: Paired T-tests before phacoemulsification and 15 days after.

\begin{tabular}{|c|c|c|}
\hline Sample 1 & \multicolumn{2}{|c|}{ V.A._PRO_OPER } \\
\hline Sample 2 & Sample 1 & Sample 2 15_DAYS_AFTER_OPER \\
\hline & 18 & 0,6222 \\
\hline Sample Size & 0,2667 & 0,5430 to 0,7014 \\
\hline Arithmetic mean & 0,2006 to 0,3327 & 0,02536 \\
\hline 95\% CI for the mean & 0,01745 & 0,1592 \\
\hline Variance & 0,1328 & 0,03753 \\
\hline Standard deviation & 0,03131 & \\
\hline Standard error of the mean & & \\
\hline
\end{tabular}




\begin{tabular}{|c|c|}
\hline \multicolumn{2}{|c|}{ Paired samples t-test } \\
\hline Mean difference & 0,3556 \\
\hline Standard deviation of differences & 0,1901 \\
\hline Standard error of mean difference & 0,04481 \\
\hline $95 \% \mathrm{CI}$ & 0,2610 to 0,4501 \\
\hline Test statistic t & 7,935 \\
\hline Degrees of Freedom (DF) & 17 \\
\hline Two-tailed probability & $\mathrm{P}<0,0001$ \\
\hline \multicolumn{2}{|c|}{ Differences } \\
\hline $\begin{array}{l}\text { Chi-squared test for Normal distribution of } \\
\text { differences }\end{array}$ & $\begin{array}{l}\text { Accept Normality }(\mathrm{P}=0,6080) \\
\text { (Chi-squared }=0,995 \mathrm{DF}=2)\end{array}$ \\
\hline
\end{tabular}

Table 5: Paired T-tests 15 days and 30 days after phacoemulsification.

\begin{tabular}{|c|c|c|}
\hline Sample 1 & \multicolumn{2}{|c|}{ V.A._15_DAYS_AFTER_OPER } \\
\hline Sample 2 & \multicolumn{2}{|c|}{ V.A._30_DAYS_AFTER_OPER } \\
\hline & Sample 1 & Sample 2 \\
\hline Sample Size & 18 & 18 \\
\hline Arithmetic mean & 0,6222 & 0,7611 \\
\hline $95 \% \mathrm{CI}$ for the mean & 0,5430 to 0,7014 & 0,6675 to 0,8548 \\
\hline Variance & 0,02536 & 0,03546 \\
\hline Standard deviation & 0,1592 & 0,1883 \\
\hline Standard error of the mean & 0,03753 & 0,04438 \\
\hline \multicolumn{3}{|c|}{ Paired samples t-test } \\
\hline Mean difference & \multicolumn{2}{|c|}{0,1389} \\
\hline Standard deviation of differences & \multicolumn{2}{|c|}{0,1461} \\
\hline Standard error of mean difference & \multicolumn{2}{|c|}{0,03443} \\
\hline $95 \% \mathrm{CI}$ & \multicolumn{2}{|c|}{0,6624 to 0,2115} \\
\hline Test statistic t & \multicolumn{2}{|c|}{4,034} \\
\hline Degrees of Freedom (DF) & \multicolumn{2}{|c|}{17} \\
\hline Two-tailed probability & \multicolumn{2}{|c|}{$\mathrm{P}=0,0009$} \\
\hline \multicolumn{3}{|c|}{ Differences } \\
\hline $\begin{array}{l}\text { Chi-squared test for Normal distribution of } \\
\text { differences }\end{array}$ & \multicolumn{2}{|c|}{$\begin{array}{l}\text { Accept Normality }(\mathrm{P}=0,3231) \\
(\text { Chi-squared }=0,976 \mathrm{DF}=1)\end{array}$} \\
\hline
\end{tabular}

Table 6: Paired T-tests before phacoemulsification and 30 days after.

\begin{tabular}{|c|c|c|}
\hline Sample 1 & \multicolumn{2}{|c|}{ V.A._PRO_OPER } \\
\hline Sample 2 & Sample 1 & 18 \\
\hline & 18 & 0,7611 \\
\hline Sample Size & 0,2667 & 0,6675 to 0,8548 \\
\hline Arithmetic mean & 0,2006 to 0,3327 & 0,03546 \\
\hline 95\% CI for the mean & 0,01765 & 0,1883 \\
\hline Variance & 0,1328 & 0,04438 \\
\hline Standard deviation & 0,03131 & 0,4944 \\
\hline Standard error of the mean & Paired samples t-test & 0,1955 \\
\hline Mean difference & & 0,04607 \\
\hline Standard deviation of differences & & 0,3972 to 0,5916 \\
\hline Standard error of mean difference & & 10,733 \\
\hline 95\% CI & & \\
\hline
\end{tabular}




\begin{tabular}{|c|c|}
\hline Degrees of Freedom (DF) & 17 \\
\hline Two-tailed probability & $\mathrm{P}<0,0001$ \\
\hline \multicolumn{2}{|c|}{ Differences } \\
\hline $\begin{array}{l}\text { Chi-squared test for Normal distribution of } \\
\text { differences }\end{array}$ & $\begin{array}{l}\text { Accept Normality }(\mathrm{P}=0,9311) \\
(\text { Chi-squared }=0,14 \mathrm{DF}=2)\end{array}$ \\
\hline
\end{tabular}

Table 7: Paired T-tests 30 days after phacoemulsification with and without applying the optimal refractive correction.

\begin{tabular}{|c|c|c|}
\hline Sample 1 & \multicolumn{2}{|c|}{ V.A._30_DAYS_AFTER_OPER } \\
\hline \multirow[t]{2}{*}{ Sample 2} & \multicolumn{2}{|c|}{ V.A._15_DAYS_AFTER_OPER_WITH_GLASSES } \\
\hline & Sample 1 & Sample 2 \\
\hline Sample Size & 18 & 18 \\
\hline Arithmetic mean & 0,7611 & 0,8944 \\
\hline $95 \% \mathrm{CI}$ for the mean & 0,6675 to 0,8548 & 0,8419 to 0,9469 \\
\hline Variance & 0,03546 & 0,01114 \\
\hline Standard deviation & 0,1883 & 0,1056 \\
\hline Standard error of the mean & 0,04438 & 0,02488 \\
\hline \multicolumn{3}{|c|}{ Paired samples t-test } \\
\hline Mean difference & \multicolumn{2}{|c|}{0,1333} \\
\hline Standard deviation of differences & \multicolumn{2}{|c|}{0,1680} \\
\hline Standard error of mean difference & \multicolumn{2}{|c|}{0,03961} \\
\hline $95 \% \mathrm{CI}$ & \multicolumn{2}{|c|}{0,04977 to 0,2169} \\
\hline Test statistic t & \multicolumn{2}{|c|}{3,367} \\
\hline Degrees of Freedom (DF) & \multicolumn{2}{|c|}{17} \\
\hline Two-tailed probability & \multicolumn{2}{|c|}{$\mathrm{P}=0,0037$} \\
\hline \multicolumn{3}{|c|}{ Differences } \\
\hline $\begin{array}{l}\text { Chi-squared test for Normal distribution of } \\
\text { differences }\end{array}$ & \multicolumn{2}{|c|}{$\begin{array}{l}\text { Accept Normality }(\mathrm{P}=0,0011) \\
(\text { Chi-squared }=10,629 \mathrm{DF}=1)\end{array}$} \\
\hline
\end{tabular}

Table 8: Paired T-tests preoperatively and 30 days after phacoemulsification with applying the optimal refractive correction.

\begin{tabular}{|c|c|c|}
\hline Sample 1 & \multicolumn{2}{|c|}{ V.A._PRO_OPER } \\
\hline \multirow[t]{2}{*}{ Sample 2} & \multicolumn{2}{|c|}{ V.A._15_DAYS_AFTER_OPER_WITH_GLASSES } \\
\hline & Sample 1 & Sample 2 \\
\hline Sample Size & 18 & 18 \\
\hline Arithmetic mean & 0,2667 & 0,8944 \\
\hline $95 \% \mathrm{CI}$ for the mean & 0,2006 to 0,3327 & 0,8419 to 0,9469 \\
\hline Variance & 0,01765 & 0,0114 \\
\hline Standard deviation & 0,1328 & 0,1056 \\
\hline Standard error of the mean & 0,03131 & 0,02448 \\
\hline \multicolumn{3}{|c|}{ Paired samples t-test } \\
\hline Mean difference & \multicolumn{2}{|c|}{0,6278} \\
\hline Standard deviation of differences & \multicolumn{2}{|c|}{0,1674} \\
\hline Standard error of mean difference & \multicolumn{2}{|c|}{0,03945} \\
\hline $95 \% \mathrm{CI}$ & \multicolumn{2}{|c|}{0,5446 to 0,7110} \\
\hline Test statistic t & \multicolumn{2}{|c|}{15,915} \\
\hline Degrees of Freedom (DF) & \multicolumn{2}{|c|}{17} \\
\hline Two-tailed probability & \multicolumn{2}{|c|}{$\mathrm{P}<0,0001$} \\
\hline \multicolumn{3}{|c|}{ Differences } \\
\hline $\begin{array}{l}\text { Chi-squared test for Normal distribution of } \\
\text { differences }\end{array}$ & \multicolumn{2}{|c|}{$\begin{array}{l}\text { Accept Normality }(\mathrm{P}=0,8386) \\
\text { (Chi-squared }=0,352 \mathrm{DF}=2 \text { ) }\end{array}$} \\
\hline
\end{tabular}


The above registration data of visual acuity, preoperatively and postoperatively, were used to perform a statistical study (Figures $4 \& 5$ ). Tables, statistics and paired T-tests for each case are listed below (Tables 3-8).

\section{Conclusion}

The clinical research concluded that the visual recovery of all patients was at a high level achieved without significant complications, within the first month after phacoemulsification. As a result, the phacoemulsification technique succeeded in keeping up with its promises, as better surgical treatment of ocular cataracts. This period of time was also sufficient for the eye to incorporate the IOL, heal the incisions, restore its physiology and stabilize its refraction. For this reason, the optometrist, who will be called to check the refraction of a patient who has undergone a phacoemulsification operation, must be conscious and avoid prescribing corrective ophthalmic lenses by the end of the first month.

\section{References}

1. Linebarger EJ (1999) Phacoemulsification and modern cataract surgery. Surv Ophthalmol 44(2): 123-147.

ISSN: 2574-1241

DOI: 10.26717/BJSTR.2019.17.002973

Pateras E. Biomed J Sci \& Tech Res

CC 9 This work is licensed under Creative

Submission Link: https://biomedres.us/submit-manuscript.php
2. Javitt JC (1993) Outcomes of cataract surgery. Improvement in visual acuity and subjective visual function after surgery in the first, second, and both eyes. Arch Ophthalmol 111(5): 686-691.

3. Charalampidou S, Loughman J, Nolan J, Stack J, Cassidy L, et al. (2011) Prognostic indicators and outcome measures for surgical removal of symptomatic nonadvanced cataract. Arch Ophthalmol 129(9): 11551161.

4. Awasthi N, Guo S, Wagner BJ (2009) Posterior capsular opacification: a problem reduced but not yet eradicated. Arch Ophthalmol 127(4): 555562.

5. Gothwal VK, Wright TA, Lamoureux EL, Pesudovs K (2010) Measuring outcomes of cataract surgery using the Visual Function Index-14. J Cataract Refract Surg 36(7): 1181-1188.

6. Lundstrom M (2011) The outcome of cataract surgery measured with the Catquest-9SF. Acta Ophthalmol 89(8): 718-723.

7. Chylack LT (1993) Longitudinal Study of Cataract Study Group, The Lens Opacities Classification System III. Arch Ophthalmol 111(6): 831-836.

8. Eirini Skiadaresi MD (2012) Subjective Quality of Vision Before and After Cataract Surgery. Arch Ophthalmol 130(11): 1377-1382.

9. Rajiv B Khandekar (2010) Visual acuity at 6 weeks after small incision cataract surgery and role of audit in predicting visual acuity. Eur J Ophthalmol 20(2): 345-352.

$\begin{array}{ll}\text { BIOMEDICAL } & \text { Assets of Publishing with us } \\ \text { RESEARCHES } & \text { - Global archiving of articles } \\ & \text { - Immediate, unrestricted online access } \\ & \text { - Rigorous Peer Review Process } \\ \end{array}$

